\title{
REVIEW
}

\section{Cooling techniques for targeted temperature management post-cardiac arrest}

\author{
Charudatt Vaity, Nawaf Al-Subaie and Maurizio Cecconi
}

\begin{abstract}
This article is one of ten reviews selected from the Annual Update in Intensive Care and Emergency Medicine 2015 and co-published as a series in Critical Care. Other articles in the series can be found online at http://ccforum.com/series/annualupdate2015. Further information about the Annual Update in Intensive Care and Emergency Medicine is available from http://www.springer.com/series/8901.
\end{abstract}

\section{Introduction}

The use of hypothermia for clinical purposes dates back to antiquity. For example, Hippocrates advocated packing wounded patients in snow and ice to reduce hemorrhage [1]. The concept that hypothermia can provide neuroprotection also has roots in the past where it was observed that infants abandoned and exposed to cold often remained viable for prolonged periods. In modern medicine, clinical interest in hypothermia developed in the 1930s and 1940s with case reports of successful resuscitation of drowning victims despite prolonged asphyxia. The first scientific paper on the clinical application of hypothermia in severe head injury patients, was published in 1943 [2]. Clinical trials on hypothermia were first started in the 1960s [3,4] but they were soon discontinued because of adverse effects and unclear benefits. Very deep hypothermia $\left(30^{\circ} \mathrm{C}\right.$ or lower) was used in most of these studies. Renewed interest in hypothermia developed in the 1980s when animal studies demonstrated that there was some benefit when mild hypothermia $\left(32-35^{\circ} \mathrm{C}\right)$ was used.

Severe neurological injury is now a recognized consequence of cardiac arrest following successful resuscitation. In post-cardiac arrest patients who survive to admission to the intensive care unit (ICU) but subsequently die, irreversible brain injury is the most common

\footnotetext{
* Correspondence: m.cecconi@nhs.net

St George's Hospital, Intensive Care Unit, London, UK
}

cause of death [5]. Cerebral damage occurs not only during cardiac arrest but also during the phase of reperfusion due to generation of free radicals and other mediators [6]. Randomized controlled trials (RCTs) using pharmacological interventions, such as thiopental [7], corticosteroids [8], lidoflazine [9] and nimodipine [10], found no benefit in improvement of neurological outcome. Targeted temperature management has been demonstrated in major studies to be a potent neuroprotective measure in post-resuscitation care following cardiac arrest [11,12]. The mechanism by which targeted temperature management works is complex and still not fully understood.

Hyperthermia following cardiac arrest has been shown to be associated with unfavorable neurological outcome. For each degree rise in temperature above $37^{\circ} \mathrm{C}$ there was an increased association with severe disability, coma or persistent vegetative state [13]. The mechanism of hyperthermia remains to be defined but several have been proposed, including increased heat production due to increased production of endogenous catecholamines, decreased heat loss or altered distribution of body heat due to vasoconstriction [14]. Loss of thermoregulatory mechanisms is seen in patients with stroke due to lesions in the anterior region of the hypothalamus [15]. One other cause of hyperthermia after cardiopulmonary resuscitation (CPR) can be infection. Infection can be secondary to pulmonary aspiration or gut translocation of bacteria and toxins following global ischemia during and after CPR [16,17].

The mechanism by which hyperthermia affects the ischemic brain is known from various animal studies. The release of neurotransmitters is increased by hyperthermia and decreased by hypothermia [18]. An additional mechanism is production of oxygen radicals during the reperfusion period. There is a 4- to 5-fold increase in oxygen radicals during the hyperthermic phase $[19,20]$. Hyperthermia also influences brain metabolism by adenosine triphosphate (ATP) depletion and by adenylate energy changes in cortical and subcortical regions. These 
changes in ATP metabolism in combination with metabolic insults are highly correlated with the release of endogenous glutamate and aspartate [21]. Hyperthermia also markedly enhances calpain activation, which is a calcium-sensitive cysteine protease, and spectrin (microtubule-associated protein-2) proteolysis in cortical pyramidal neurons soon after the onset of reperfusion, an effect that becomes marked by 4 and 24 hours, in association with morphological evidence of irreversible neuronal injury [22].

There are several mechanisms by which targeted temperature management may improve neurological outcome when used after reperfusion. Hypothermia reduces the cerebral metabolic rate for oxygen $\left(\mathrm{CMRO}_{2}\right)$ by $6 \%$ for every $1^{\circ} \mathrm{C}$ reduction in brain temperature $>28^{\circ} \mathrm{C}$. This effect is partly due to reduced normal electrical activity [23]. Targeted temperature management is thought to suppress many of the chemical reactions associated with reperfusion injury. These reactions, as mentioned previously, are associated with hyperthermia and include free radical production, excitatory amino acid release, and calcium shifts, which can in turn lead to mitochondrial damage and apoptosis. Hypothermia attenuates pro-apoptotic signals, such as cytochrome c release, Fas and Bax upregulation, and caspase activation and activates antiapoptotic mechanisms, such as the Erk1/2 pathway and the Akt pathway [24]. The expression of p53 is enhanced by hypothermia, promoting repair after focal ischemia [25]. The levels of neuron-specific enolase, a marker of neuron death, are also reduced in patients treated with hypothermia following CPR [26].

Rapid rewarming exaggerates neural injury partly by modulating cellular and molecular mechanisms, as discussed above. In experimental models of traumatic brain injury (TBI) and stroke, rapid rewarming led to loss of cerebral autoregulation. Controlled rewarming, as in targeted temperature management, protects vascular reactivity and also reduces the oxygen radical-mediated endothelial and smooth muscle cell injury in brain vessels $[27,28]$.

Targeted temperature management aims to attenuate this secondary cascade of events and to prevent or minimize the impact of this secondary injury mechanism [29-31]. Targeted temperature management has become standard therapy following cardiac arrest. It is recommended by major organizations providing resuscitation guidelines, including the European Resuscitation Council, International Liaison Committee on Resuscitation (ILCOR) and American Heart Association [32,33].

The term 'targeted temperature management' has replaced 'therapeutic hypothermia' or 'mild hypothermia' to emphasizethe importance of defining a complete temperature profile. Manipulating the body temperature, intentionally, has become oneof the treatment strategies with an impact on outcome post-cardiac arrest. Targeted temperature management can be dividedinto three phases:

1) intentional change from current temperature to lower temperature - 'induction';

2) maintenance of that temperature for a time 'maintenance'; and

3) change to a new temperature value by increase in temperature at a specific rate to a normothermic target - 'rewarming'.

In earlier studies, there was emphasis on rapid introduction of cooling [34], but a recent RCT did not demonstrate any benefit in terms of speed to achieve therapeutic hypothermia in comparison to targeted temperature management [11]. Induction of hypothermia is not easy and can be associated with complications, including decreased cardiac output, arrhythmias, bleeding diathesis, electrolyte disturbances, and insulin resistance. Therefore, cooling should be achieved in an easy, controllable manner. The emphasis of targeted temperature management is tight maintenance of temperature.

\section{Cooling techniques}

Currently available cooling techniques can be divided into three main categories:

1) Conventional cooling techniques

2) Surface cooling systems

3) Intravascular cooling systems.

\section{Conventional cooling systems}

Cold saline, crushed ice or ice bags have been used as the easiest way to induce hypothermia. Cold saline infusion has been shown to be effective in inducing hypothermia but not so effective in maintaining target temperature [35]. The main advantages of cold intravenous fluid are its easy availability and low cost. Volumes of up to two liters of intravenous fluids can be safely administered post-cardiac arrest [36]. Some studies have shown that saline or Ringer's lactate in combination with ice bags can achieve acceptable reductions in temperature [37].

Conventional cooling methods, in addition to being useful and cost-effective for the induction of hypothermia, can be used as adjuncts to other more advanced cooling devices [38]. The disadvantages of using conventional cooling techniques are that they are labor intensive; moreover, unintentional cooling below target temperature is common and can have deleterious effects [39]. Conventional cooling systems are also less effective at maintaining temperature when compared to surface or intravascular cooling systems [40]. 


\section{Surface cooling systems}

Surface cooling systems work by circulating cold fluid or cold air through blankets or pads that are wrapped around the patient. There is a range of products currently available, including cooling blankets (Curewrap $^{\mathrm{Tx}}$ with CritiCool by MTRE, Yavne, Israel; Kool-Kit ${ }^{\circ}$ with Blanketrol III, by Cincinnati Sub-Zero, Cincinnati, OH) and surface pads (InnerCool STX by Philips, Best, Netherlands; Artic Sun by Medivance, Louisville, CO) (Table 1). A study comparing the Cincinnati SubZero system, a water-circulating cooling blanket, to the Medivance Artic Sun ${ }^{\circ}$ hydrogel-coated water-circulating energy transfer pads, showed that the pads were superior in controlling fever in critically ill neurologic patients [41]. A study comparing the Arctic Sun surface system with the invasive intravascular Coolgard (Zoll, Chelmsford, MA) system in post-cardiac arrest patients showed similar survival to hospital discharge and comparable neurologic function at follow-up. Interpretation of device efficacy (cooling/rate), though, was limited by concurrent use of cold saline and ice bags [42]. The EMCOOLS cooling system (Vienna, Austria) uses adhesive non-invasive HypoCarbon ${ }^{\bullet}$ pads with a carbon-based cooling gel and provides cooling rates of $3.5^{\circ} \mathrm{C} / \mathrm{h}$. There is no feedback system or computer control. The technology uses the thermal conductivity properties of the carbon-based gel to provide a highly effective cooling rate. Because if its ease of application and high cooling rate it can be used in the prehospital setting [43].

The advantages with using surface systems are ease of application and rapid initiation of treatment. Most of the devices have computerized auto-feedback mechanisms allowing the user to set target temperature and the system modifies the water temperature using the feedback from patient's skin and core temperature sensors.

The disadvantages of these systems are rare risk of skin burns and skin irritation [44]. The initiation of hypothermia varies between different devices and can range from 2-8 hours. Maintenance of temperature may also be difficult. Shivering is more commonly seen with surface systems than with other systems [41], which may necessitate the use of muscle relaxants.

\section{Intravascular cooling systems}

There are two devices currently available on the market: Thermoguard XP temperature management system (Zoll) and InnerCool RTx with Accutrol catheter (Philips).

The Thermoguard XP system uses percutaneously placed central venous catheters, which can be placed in subclavian, internal jugular or femoral veins. Temperature control is achieved by circulating cool or warm saline in a closed loop through the catheter's balloon [45]. Zoll offers different types of catheters, which can be used to adapt to different clinical needs (Table 2).

The InnerCool RTx endovascular cooling system uses a specific catheter, Accutrol, which has an integrated temperature sensor for precise control of temperature in all three phases of temperature management, without the possibility of lag in core temperature measurement that may be inherent with rectal or bladder temperature probes. There is no additional central venous access provided with the catheter [46].

Both these systems have computerized temperature control with an auto-feedback mechanism. The intravascular cooling systems provide precise temperature control during maintenance and rewarming phases of temperature management. There are fewer incidences of failure to reach target temperature and less overcooling than with other systems. There is also less shivering compared to surface devices [47]. Despite these advantages, however, there was no difference in outcome when compared to surface cooling systems [48]. There is an added risk of catheter-related bloodstream infection, venous thrombosis and complications related to insertion of intravascular lines.

\section{Other cooling methods}

An extracorporeal cooling method using KTEK-3 (Kawasumi, Tokyo, Japan) has been used in postcardiac arrest patients in Japan [49]. This technique can only be employed in places where an extracorporeal device is available and needs trained personnel to deliver care. RhinoChill ${ }^{\circ}$ is a novel intranasal cooling system, designed to provide early and rapid initiation of patient cooling [50]. It was shown to effectively reduce temperature in pre-hospital intra-arrest patients [51]. There is no temperature feedback mechanism and the main

Table 1 Surface cooling devices

\begin{tabular}{llll}
\hline Company & Device & Type of cooling & Salient feature \\
\hline MTRE & CritiCool & Surface blanket & Water-filled body shaped wrap covers the skin \\
Philips & InnerCool STX & Surface pads & Non-adhesive surface pads \\
EMCOOLS & Flexipads & Surface pads & Hypocarbon-based pads \\
C.R. Bard & ArticSun & Surface pads & Adhesive pads \\
\hline
\end{tabular}

This table shows commonly available devices and is by no means complete. 
Table 2 Catheter specifications for the Thermoguard XP system (Zoll)

\begin{tabular}{|c|c|c|c|c|}
\hline Catheter name & Cool line ${ }^{\oplus}$ & Solex ${ }^{\circledast}$ & $\mathrm{ICY}{ }^{\odot}$ & Quattro $^{\oplus}$ \\
\hline Number of heat exchange balloons & 2 & Serpentine balloon & 3 & 4 \\
\hline Number of infusion lumens & 3 & 3 & 3 & 3 \\
\hline Insertion site & Subclavian Internal jugular Femoral & Internal jugular & Femoral & Femoral \\
\hline Length & $22 \mathrm{~cm}$ & $25 \mathrm{~cm}$ & $38 \mathrm{~cm}$ & $45 \mathrm{~cm}$ \\
\hline
\end{tabular}

Adapted from Zoll Catheter Specification Sheet [45].

application of this device is in the pre-hospital setting for induction of hypothermia.

There have been case reports on the use of continuous renal replacement therapy (CRRT) for induction and maintenance of hypothermia [52,53]. Selective brain cooling by hypothermic retrograde jugular vein flush and intranasally has been investigated in animal models and this may be relevant in conditions where whole body hypothermia may be detrimental, such as cardiac arrest associated with polytrauma [54,55]. Further investigations are being conducted into use of intrapulmonary perflurochemical fluids for induction and maintenance of hypothermia and also to support gas exchange and pulmonary structure [56]. The esophageal route is also being investigated, because of the close proximity of the esophagus to blood flow from the heart and great vessels. Initial animal and mathematical studies have shown that the esophageal route is safe and effective for inducing, maintaining and reversing hypothermia $[57,58]$.

\section{Conclusion}

Various cooling methods and techniques are currently available to achieve targeted temperature management. There are three phases of targeted temperature management: Induction, maintenance and rewarming. Different cooling methods vary in their effectiveness for each phase of cooling. The most beneficial time to commence hypothermia is debatable. The current recommendation by ILCOR is to start hypothermia as soon as possible and to aim for a temperature between $32-34^{\circ} \mathrm{C}$. However, a recently concluded RCT showed no evidence to support inducing hypothermia, but an emphasis on maintenance of temperature and avoiding pyrexia; there was also no association of time to target temperature and neurological outcome [11].

A study comparing different cooling methods in ICU patients concluded that water circulating blankets, gelpads and intravascular devices are almost equivalent for inducing hypothermia but intravascular devices are superior in maintaining target temperature [40]. The performances of the different devices may change as technology evolves; however, each method has its own limitations and the combination of conventional methods and automatic computer-processed feedback devices seems a safe option.
Temperature management is no longer just a question of whether a patient is cool, but has evolved into a complex treatment management procedure. It is, therefore, paramount to ensure precise control of temperature during all three phases of temperature management, especially during the phase of rewarming during which a passive, uncontrolled rise in temperature can be deleterious to the patient. The development of different devices aimed at greater precision in monitoring and managing temperature in cardiac arrest patients will help to make treatment safe and easy.

This review on the different cooling methods is written at a time where news on targeted temperature management breaks daily and, therefore, cannot claim to be complete but rather a snap shot in a rapidly developing field. With so many different devices available and the likelihood of new devices emerging, the device used should be selected according to its ability to effectively maintain temperature within the therapeutic range with the fewest possible adverse effects while being as minimally invasive as possible.

\section{Abbreviations \\ ATP: Adenosine triphosphate; $\mathrm{CMRO}_{2}$ : Cerebral metabolic rate for oxygen; CRRT: Continuous renal replacement therapy; ICU: Intensive care unit; ILCOR: International liaison committee on resuscitation; RCT: Randomized controlled trial.}

\section{Competing interests}

The authors declare that they have no competing interests.

\section{Declarations}

The publication charges for this article were funded by the corresponding author's institution.

Published online: 16 March 2015

\section{References}

1. Hippocrates (460-375 BC) De Vetere Medicina.

2. Fay T. Observations on generalized refrigeration in cases of severe cerebral trauma. Assoc Res Nerv Ment Dis Proc. 1943;24:611-9.

3. Rosomoff HL, Safar P. Management of the comatose patient. Clin Anes. 1965;1:244-58

4. Lazorthes G, Campan L. Moderate hypothermia in the treatment of head injuries. Clin Neurosurg. 1964;12:293-9.

5. Laver S, Farrow C, Turner D, Nolan J. Mode of death after admission to an intensive care unit following cardiac arrest. Intensive Care Med. 2004;30:2126-8.

6. Negovsky VA. Postresuscitation disease. Crit Care Med. 1988;16:942-6.

7. Brain Resuscitation Clinical Trial I Study Group. Randomized clinical study of thiopental loading in comatose survivors of cardiac arrest. N Engl J Med. 1986;314:397-403. 
8. Jastremski M, Sutton-Tyrrell K, Vaagenes P. Glucocorticoid treatment does not improve neurological recovery following cardiac arrest. JAMA. 1989;262:3427-30.

9. Abramson N. A randomized clinical-study of a calcium-entry blocker (lidoflazine) in the treatment of comatose survivors of cardiac-arrest. N Engl J Med. 1991;324:1225-31.

10. Roine $\mathrm{R}$, Kaste $\mathbf{M}$, Kinnunen $\mathrm{A}$, et al. Nimodipine after resuscitation from out-of-hospital ventricular-fibrillation - a placebo-controlled, double-blind randomized trial. JAMA. 1990;264:3171-7.

11. Nielsen N, Wetterslev J, Cronberg T. Targeted temperature management at 33 C versus 36 C after cardiac arrest. N Engl J Med. 2013;369:2197-206.

12. The Hypothermia after Cardiac Arrest Study Group. Mild therapeutic hypothermia to improve the neurologic outcome after cardiac arrest. N Engl J Med. 2002;346:549-56.

13. Zeiner A, Holzer M, Sterz F. Hyperthermia after cardiac arrest is associated with an unfavorable neurologic outcome. Arch Intern Med. 2001;161:2007-12.

14. Safar P. Resuscitation from clinical death: pathophysiologic limits and therapeutic potentials. Crit Care Med. 1988;16:923-41.

15. Powers JH, Scheld WM. Fever in neurologic diseases. Infect Dis Clin North Am. 1996;10:45-66.

16. Sterz F, Safar P, Diven W, et al. Detoxification with hemabsorption after cardiac arrest does not improve neurologic recovery. Review and outcome study in dogs. Resuscitation. 1993;25:137-60

17. Stone BJ, Chantler PJ, Baskett PJF. The incidence of regurgitation during cardiopulmonary resuscitation: a comparison between the bag valve mask and laryngeal mask airway. Resuscitation. 1998;38:3-6.

18. Sternau L, Globus MYT, Dietrich WD, Martinez E, Busto R, Ginsberg MD. Ischemia-induced neurotransmitter release: effects of mild intraischemic hyperthermia. In: Globus M, Dietrich WD, editors. The Role of Neurotransmitters in Brain Injury. New York: Plenum Press; 1992. p. 33-8.

19. Globus MY, Busto R, Lin B, et al. Detection of free radical activity during transient global ischemia and recirculation: Effects of intraischemic brain temperature modulation. J Neurochem. 1995;65:1250-6.

20. Kil HY, Zhang J, Piantadosi CA. Brain temperature alters hydroxyl radical production during cerebral ischemia/reperfusion in rats. J Cereb Blood Flow Metab. 1996;16:100-6.

21. Madl JE, Allen DL. Hyperthermia depletes adenosine triphosphate and decreases glutamate uptake in rat hippocampal slices. Neuroscience. 1995;69:395-405.

22. Morimoto T, Ginsberg MD, Dietrich WD, Zhao W. Hyperthermia enhances spectrin breakdown in transient focal cerebral ischemia. Brain Res. 1997:746:43-51.

23. Steen PA, Newberg L, Milde JH, Michenfelder JD. Hypothermia and barbiturates: individual and combined effects on canine cerebral oxygen consumption. Anesthesiology. 1983;58:527-32.

24. Han HS, Park J, Kim J, Suk K. Molecular and cellular pathways as a target of therapeutic hypothermia: pharmacological aspect. Curr Neuropharmacol. 2012;10:80-7.

25. Tomasevic $G$, Kamme F, Stubberöd $P$, et al. The tumor suppressor p53 and its response gene p21WAF1/Cip1 are not markers of neuronal death following transient global cerebral ischemia. Neuroscience. 1999;90:781-92.

26. Rundgren $M$, Karlsson $\mathrm{T}$, Nielsen $\mathrm{N}$, et al. Neuron specific enolase and S-100B as predictors of outcome after cardiac arrest and induced hypothermia. Resuscitation. 2009;80:784-9.

27. Povlishock JT, Wei EP. Posthypothermic rewarming considerations following traumatic brain injury. J Neurotrauma. 2009;26:333-40.

28. Linares G, Mayer SA. Hypothermia for the treatment of ischemic and hemorrhagic stroke. Crit Care Med. 2009;37:S243-9.

29. Andrews PJD, Sinclair HL, Battison CG, et al. European society of intensive care medicine study of therapeutic hypothermia $\left(32-35^{\circ} \mathrm{C}\right)$ for intracranial pressure reduction after traumatic brain injury (the Eurotherm3235Trial). Trials. 2011;12:8.

30. Benz-Woerner J, Delodder F, Benz R, Cueni-Villoz N. Body temperature regulation and outcome after cardiac arrest and therapeutic hypothermia. Resuscitation. 2012:83:338-42.

31. Polderman $\mathrm{KH}$, Herold I. Therapeutic hypothermia and controlled normothermia in the intensive care unit: Practical considerations, side effects, and cooling methods. Crit Care Med. 2009;37:1101-20.

32. Peberdy MA, Callaway CW, Neumar RW, et al. Part 9: post-cardiac arrest care: 2010 American Heart Association Guidelines for Cardiopulmonary
Resuscitation and Emergency Cardiovascular Care. Circulation. 2010;122:S768-86.

33. Nolan JP, Neumar RW, Adrie C, et al. Post-cardiac arrest syndrome: Epidemiology, pathophysiology, treatment, and prognostication. Resuscitation. 2008;79:350-79.

34. Bernard SA, Mac Jones BC, Horne MK. Clinical trial of induced hypothermia in comatose survivors of out-of-hospital cardiac arrest. Ann Emerg Med. 1997;30:146-53.

35. Kliegel A, Janata A, Wandaller C, et al. Cold infusions alone are effective for induction of therapeutic hypothermia but do not keep patients cool after cardiac arrest. Resuscitation. 2007;73:46-53.

36. Kim F, Olsufka M, Carlbom D, et al. Pilot study of rapid infusion of $2 \mathrm{~L}$ of $4 \mathrm{C}$ normal saline for induction of mild hypothermia in hospitalized, comatose survivors of out-of-hospital cardiac arrest. Circulation. 2005;112:715-9.

37. Larsson I, Wallin E, Rubertsson S. Cold saline infusion and ice packs alone are effective in inducing and maintaining therapeutic hypothermia after cardiac arrest. Resuscitation. 2010;81:15-9.

38. Kliegel $A$, Losert $H$, Sterz $F$, et al. Cold simple intravenous infusions preceding special endovascular cooling for faster induction of mild hypothermia after cardiac arrest - a feasibility study. Resuscitation. 2005;64:347-51.

39. Merchant RM, Abella BS, Peberdy MA, et al. Therapeutic hypothermia after cardiac arrest: Unintentional overcooling is common using ice packs and conventional cooling blankets. Crit Care Med. 2006;34:S490-4.

40. Hoedemaekers C, Ezzahti M, Gerritsen A. Comparison of cooling methods to induce and maintain normo-and hypothermia in intensive care unit patients: a prospective intervention study. Crit Care. 2007;11:R91.

41. Mayer SA, Kowalski RG, Presciutti M, et al. Clinical trial of a novel surface cooling system for fever control in neurocritical care patients. Crit Care Med. 2004;32:2508-15.

42. Tømte $\varnothing$, Drægni T, Mangschau A, et al. A comparison of intravascular and surface cooling techniques in comatose cardiac arrest survivors. Crit Care Med. 2011;39:443-9.

43. EMCOOL. Available at: http://www.emcools.com/en/home.aspx

44. Varon J, Acosta P, Wintz R, Mendoza N. Unusual side effect from hydrogel pads during therapeutic hypothermia. Resuscitation. 2008;78:248-9.

45. IVTM Intravascular Temperature Management Catheter Specifications. http://www.zoll.com/uploadedFiles/Public_Site/Products/Catheters/ Catheters_spec_sheet.pdf. Accessed Nov 2014

46. High performance temperature management RTx Endovascular and STx Surface Cooling Systems. http://incenter.medical.philips.com/doclib/ enc/6293662/Philips_InnerCool_Advanced_Temperature_Modulation_ Therapy_-_Enhancing_patient_care.pdf\%3ffunc\%3ddoc.Fetch\%26nodeid \%3d6293662\%26vernum\%3d4. Accessed Nov 2014

47. Lyden ARL, $\mathrm{Ng} \mathrm{K}$, et al. Intravascular cooling in the treatment of stroke (ICTuS): Early clinical experience. J Stroke Cerebrovasc Dis. 2005;14:107-14.

48. Gillies M, Pratt R, Whiteley $C$, et al. Therapeutic hypothermia after cardiac arrest: a retrospective comparison of surface and endovascular cooling techniques. Resuscitation. 2010;81:1117-22.

49. Soga T, Nagao K, Kikushima K, et al. Mild therapeutic hypothermia using extracorporeal cooling method in comatose survivors after out-of-hospital cardiac arrest. Circulation. 2006;114:II_1190.

50. Rhinochill Advantage. Available at: http://www.benechill.com/wp/rhinochilltrade/ems-use/. Accessed Nov 2014.

51. Castrén M, Nordberg P, Svensson L, et al. Intra-arrest transnasal evaporative cooling: a randomized, prehospital, multicenter study (PRINCE: Pre-ROSC IntraNasal Cooling Effectiveness. Circulation. 2010;122:729-36.

52. Ma Y, Ning B, Cao W, et al. Good neurologic recovery after cardiac arrest using hypothermia through continuous renal replacement therapy. Am J Emerg Med. 2013;31:1720.e1-3.

53. Karacan $H$, Valentin A, Carl P. Mild therapeutic hypothermia after cardiac arrest through continuous dialysis. Ugeskr Laeger. 2009;171:1396-400.

54. Wen $Y$, Huang M, Lin M. Rapid brain cooling by hypothermic retrograde jugular vein flush. J Trauma. 2005;58:577-81.

55. Covaciu L, Allers M, Enblad P, Lunderquist A. Intranasal selective brain cooling in pigs. Resuscitation. 2008;76:83-8.

56. Yang $\mathrm{S}$, Jeng M, McShane R, et al. Cold perfluorochemical-induced hypothermia protects lung integrity in normal rabbits. Biol Neonate. 2005;87:60-5. 
57. Kulstad E, Metzger A, Courtney D, Rees J. Induction, maintenance, and reversal of therapeutic hypothermia with an esophageal heat transfer device. Resuscitation. 2013;84:1619-24.

58. Vaicys V, Eason A, Schieber J, Kulstad E. Therapeutic hypothermia induction via an esophageal route - a computer simulation. Am J Emerg Med. 2012;30:932-5. 